\title{
GCU
}

Glasgow Caledonian

University

University for the Common Good

\section{Prospective observational study of the impact of vaginal surgery (pelvic organ prolapse with or without urinary incontinence) on female sexual function}

Tyagi, Veenu; Perera, Mahesh; Guerrero, Karen; Hagen, Suzanne; Pringle, Stewart

Published in:

International Urogynecology Journal

DOI:

10.1007/s00192-017-3500-7

Publication date:

2018

Document Version

Author accepted manuscript

Link to publication in ResearchOnline

Citation for published version (Harvard):

Tyagi, V, Perera, M, Guerrero, K, Hagen, S \& Pringle, S 2018, 'Prospective observational study of the impact of vaginal surgery (pelvic organ prolapse with or without urinary incontinence) on female sexual function',

International Urogynecology Journal, vol. 29, no. 6, pp. 837-845. https://doi.org/10.1007/s00192-017-3500-7

\section{General rights}

Copyright and moral rights for the publications made accessible in the public portal are retained by the authors and/or other copyright owners and it is a condition of accessing publications that users recognise and abide by the legal requirements associated with these rights.

Take down policy

If you believe that this document breaches copyright please view our takedown policy at https://edshare.gcu.ac.uk/id/eprint/5179 for details

of how to contact us. 
1 Prospective Observational study of the impact of vaginal surgery (Pelvic Organ

2 Prolapse +/- Urinary Incontinence) on female sexual function.

\section{Authors:}

$4 \quad$ Veenu Tyagi (MRCOG)

5 Consultant subspecialist Urogynaecologist,

6 NHS Greater Glasgow and Clyde,

7 Queen Elizabeth University Hospital , 1345 Govan Road, Glasgow, G51 4TF

$8 \quad$ Veenu.Tyagi@ggc.scot.nhs.uk

900441412012820

11 Dr Mahesh Perera (MRCOG),

12 Consultant Obstetrician and Gynaecologist,

13 NHS Greater Glasgow and Clyde,

14 Princes Royal Maternity Hospital, 16 Alexandra Parade, Glasgow, G16 2ER

$15 \quad$ Mahesh.Perera@ggc.scot.nhs.uk

$16 \quad 00441412115248$

18 Dr Karen Guerrero (FRCOG),

19 Consultant subspecialist Urogynaecologist 
20 NHS Greater Glasgow and Clyde

21 Queen Elizabeth University Hospital,1345 Govan Road, Glasgow, G51 4TF

22 Karen.Guerrero@ggc.scot.nhs.uk

$23 \quad 00441412012820$

24

25 Professor Suzanne Hagen (PhD CStat CSci)

26 Interventions Programme Director

27 Nursing, Midwifery and Allied Health Professions Research Unit

28 Cowcaddens Road, Glasgow G4 0BA

29 s.hagen@gcu.ac.uk

$30 \quad 00441413318104$

31

32

33 Dr Stewart Pringle (FRCOG)

34 Consultant Gynaecologist

35 NHS Greater Glasgow and Clyde

36 Queen Elizabeth University Hospital_ 1345 Govan Road, Glasgow, G51 4TF

37 Stewart.Pringle@ggc.scot.nhs.uk 
$40 \quad$ Veenu.Tyagi@ggc.scot.nhs.uk

4100441412012820

43 Author's participation with the manuscript:

44 VT: project design, data collection, data analysis, writing of manuscript

45 MP: data collection, writing of manuscript

46 KG: project design, data collection, data analysis, writing of manuscript

$47 \mathrm{SH}$ : Data analysis, writing of manuscript

48 SP: manuscript writing

49 Disclosure

50 All the authors have nothing to disclose.

52 Conflict of Interest

53 The authors declare that they have no conflict of interest.

54 Abstract: 188

55 Main manuscript: 3323 


\section{Abstract}

\section{Introduction and Hypothesis:}

There is a difference of opinion in the literature as to whether or not pelvic organ prolapse (POP) is a direct cause of FSD. Sexual function in women is negatively impacted by presence of urinary symptoms. Sexual dysfunction(SD) might be improved, unchanged or worsened by pelvic floor surgery.

\section{Methods:}

In this study we observed the SD and impact of surgical intervention on female sexual function using validated questionnaire (PISQ-12) in women undergoing pelvic organ prolapse +/- urinary incontinence surgery. 200 women were recruited and followed up 6 and 12 months post operatively.

\section{Results:}

Sexual function as measured by the PISQ-12 improved after surgery irrespective of the nature of surgery or the patient's past gynaecology history. Improvement in sexual function was seen by 6 months (97 patients) post-surgery $(p<0.05)$ after which(assessed at 12 months - 80 patients) no further change in PISQ-12 was observed. Improved sexual function was associated with better patient satisfaction post-operatively.

\section{Conclusions:}

Sexual function improved after surgery irrespective of nature of surgery and patient past gynaecology history. Our study will help in counselling women with POP and/or UI undergoing surgery about potential improvement in sexual function. 
80 Keywords: Female sexual function, validated questionnaire, vaginal surgery

81 Summary: Majority of women will have improvement in sexual function after 82 prolapse +/- incontinence surgery and this is strongly positively associated with 83 patient satisfaction.

84

85

86

87

88

89

90

91

92

93

94

95

96

97 


\section{INTRODUCTION}

99 Female Sexual Dysfunction (FSD) is a common problem, with data from the National 100 Health and Social Life Survey showing that $43 \%$ of women aged 18-59 years 101 experiencing some form of FSD(1). The aetiology of FSD is multifactorial, with hormonal, psychological, anatomical, vascular and neurogenic elements all being 103 possible aetiological factors(2).

Pelvic Organ Prolapse (POP) and urinary incontinence (UI) form a major health burden to women affecting $41-65 \%$ of women. Large population study suggests that the prevalence of stage three or four prolapse is in the range of $2-11 \%(3,4)$. An epidemiological study reported UI to affect up to $41 \%$ of the women. (5). At least 1 in 3 parous women undergo at least one surgery for these conditions by the age of 80 years (6). Women with POP and /or UI are at higher risk of sexual dysfunction $(7,8$, $9,10,11)$ compared to those without.

111 Traditionally pelvic floor surgeons have assessed the outcome of vaginal repair surgery by the degree of restoration of normal pelvic anatomy. Increasingly, however the effect of prolapse surgery upon a woman's sexual function is being used as an outcome measure of the success of surgical repair $(12,13)$, especially since the introduction of vaginal mesh repairs for prolapse (14).

There is a difference of opinion in the literature however as to whether or not Pelvic

117 Organ Prolapse (POP) is a direct cause of FSD. It may not be the prolapse itself but rather the associated coital incontinence that predicts sexual dysfunction. Likewise, it appears that vaginal anatomy per se is not an independent factor in the aetiology of 
120 FSD: neither vaginal calibre, nor length, nor atrophy, nor menopausal status have a

121 direct influence on the presence of $\operatorname{FSD}(22)$.

\section{AIMS}

123 In this study we aimed to assess the incidence of FSD in a group of sexually active 124 women with stress urinary incontinence (SUI) and/or pelvic organ prolapse (POP) 125 awaiting surgical management. The secondary aim was to determine whether 126 vaginal surgery for prolapse or UI leads to alteration in sexual function and to 127 compare SF in subjects undergoing POP or UI surgery alone with POP surgery 128 combined with UI surgery.

\section{STUDY POPULATION}

130 The study was co-ordinated from the Department of Urogynaecology at the South 131 Glasgow University Hospital in their established Urogynaecology and Pelvic Floor 132 Dysfunction Research Unit. All women undergoing any type of POP repair and/ or urinary incontinence surgery were invited to participate in the study. 200 women

134 were recruited through the Urogynaecology clinics across the service over a 12month period from June 2011 to May 2012. All women gave written informed consent to be involved in the study.

\section{FUNDING}

138 Project was funded by the Department of Urogynaecology, South Glasgow 139 University Hospital. 
1. Women on the waiting list for surgical repair of POP, UI procedure or both, and;

2. Who have been sexually active in the last 6 months and expect to remain so post-operatively, or;

\section{EXCLUSION CRITERIA}

1. Women under 18 years of age

2. Women unable to understand information leaflet

3. Women unable to complete the questionnaire

\section{DATA COLLECTION}

Patient's demographics and details about their surgical procedure(s) were obtained from the patient's hospital records.

\section{METHODOLOGY}

This was a prospective observational study. Ethical approval was obtained from West of Scotland Ethics Committee. Reference number: 10/S0709/69; 16/03/2011.

Women complaining of symptomatic pelvic organ prolapse and/or SUI who were on the waiting list for pelvic prolapse surgery (POP) +/- urinary incontinence (UI) surgery were recruited at preoperative assessment visit or during hospital admission for their procedure. Consenting participants completed the preoperative questionnaire which included primary and secondary outcome measures prior to surgery.

At 6 and 12 months after surgery a further set of questionnaire(baseline questionnaire and a self designed questionnaire appendix 1) was sent to women by 
163 post, along with a stamped addressed envelope, to be completed at home and 164 returned. Women who did not respond within 2 weeks were sent a reminder letter and questionnaire, and then they were contacted by telephone if there was no response after a further 2 weeks.

\section{Primary outcome}

Primary Outcome was to assess incidence of sexual dysfunction by condition specific validated quality of life assessment tool Prolapse/urinary incontinence sexual questionnaire short form (PISQ 12) score. (Rogers 2001, 2003)

\section{Secondary outcomes}

172 Secondary outcome was the change in PISQ-12 and International consultation on

173 Incontinence Questionnaire - Vaginal Symptoms (ICIQ-VS) between baseline and 6 174 and 12 months after surgery. We also assessed urinary incontinence symptom 175 distress and its life impact at 6 and 12 months using urogenital distress inventory short form (UDI-6) and Incontinence Impact Questionnaire IIQ-7. Patient satisfaction with surgery was measured using a study specific, non validated instrument 178 (appendix 1) at 6 and 12 months.

\section{Analysis}

We tabulated descriptive statistics, reporting baseline demographics and clinical characteristics with means and SDs, or medians and IQRs as appropriate. A paired t-test was used to compare baseline, 6 month and 12 month scores, and analysis of variance to test for differences between surgery groups and post operative satisfaction levels. Data were analysed in SPSS version 19 and a $5 \%$ level of significance was used throughout. 
188 Two hundred women were recruited of which $180(90 \%)$ returned completed baseline questionnaires. At 6-months 97 (48.5\%) patients returned completed questionnaires. $87(43.5 \%)$ questionnaires were returned completed at 12-months 191 (Figure 1).

The mean age of participants was 54.4 years (SD 10.1). All women except 3 were parous with a median parity of 2 (range $0-5)$. $121(67.2 \%)$ women were postmenopausal out of which $15(8.3 \%)$ were on HRT at the time of their surgery. A significantly higher proportion of women who had surgery for prolapse were menopausal (Chi-square $=9.412, \mathrm{df}=2, \mathrm{P}=0.009)$. The majority of women who had surgery for POP (98\%) had stage II or greater prolapse (Table 1).

Thirty-seven (19.5\%) women had POP surgery in the past, of which the majority had conventional prolapse surgery without the use of mesh. Four $(2.2 \%)$ patients had surgery using mesh graft and $2(1.1 \%)$ had both conventional and surgery using mesh. Seventeen $(9.5 \%)$ patients had a previous UI procedure. One hundred and sixteen $(68 \%)$ patients had no documented urinary symptoms (table 1).

A total of 130 women underwent POP surgery, 29 had UI surgery and 21 women had both POP and UI surgery (Table 2).

\section{Sexual function}

Overall the mean baseline PISQ-12 score in our study population was 30.54 (SD 6.55). There was no statistical difference in baseline PISQ-12 in women as per their age, parity, menopausal status or whether they had previous POP and /or UI surgery(table 3). There was also no statistically significant difference in the baseline 
210 PISQ-12 between groups of women awaiting only POP surgery or only UI surgery or

211 both POP and UI surgery (Table 4).

212 For all women the mean PISQ-12 score increased (improved) to 33.4 (SD 7.36) at 6 months and 33.5 (SD 7.40) at 12 months (Table 3). The improvement in PISQ-12 score from baseline to 6 and 12 months was statistically significant (Table 3 ) but not from 6 months to 12 months. The improvement in PISQ-12 was not significantly different between the groups of women having POP surgery, UI surgery or both POP and UI surgery (ANOVA F=2.266, $d f=2, p=0.109$ ). It was also not influenced by any of the above mentioned demographic characteristics.

219 Improvements in UDI-6, VS and IIQ-7 scores from baseline to 6 months were statistically significant but not from 6 to 12 months, similar to PISQ-12 scores (Table 4).

222 No significant difference was seen between surgery types (no mesh, vaginal mesh for prolapse, mesh for UI, abdominal mesh for prolapse) in the change in PISQ-12 score from baseline to 6 months (ANOVA $F=1.463, \mathrm{df}=3, \mathrm{p}=0.230$ ), specifically there was no difference between women having prolapse surgery with and without mesh (mean difference -0.99 , standard error $1.49, \mathrm{p}=0.510$ ).

\section{Other outcomes}

Improvement in UDI-6 and IIQ-7 scores from baseline to 6 months was significantly different between the three surgery groups (ANOVA $F=15.9, \mathrm{df}=2, \mathrm{P}<0.005$ and $F$ $230=17.9, \mathrm{df}=2, \mathrm{p}<0.005$ respectively). There was significantly more improvement in 231 both UDI and IIQ scores for those women who had prolapse surgery alone 232 compared to those women who had UI surgery only or those who had combined UI 
and prolapse surgery. Improvement in VS scores from baseline to 6 months was not significantly different between groups (ANOVA $F=1.757, d f=2, p=0.178)$.

\section{Relationship with patient satisfaction}

Seventy-seven (83\%) women at 6 months and $60(78 \%)$ women at 1 year reported being either satisfied or very satisfied with their surgical outcome. Being satisfied with surgery at 6 months (not satisfied / satisfied / very satisfied) was significantly associated with improvement in PISQ-12 score from baseline to 6-months (ANOVA $F=5.915, d f=2, p=0.004)$.

Improvements in UDI-6 (ANOVA F $=4.293, \mathrm{df}=2, \mathrm{p}=0.017$ ) and VS scores (ANOVA $\mathrm{F}=3.771, \mathrm{df}=2, \mathrm{p}=0.025)$ at 6 months from baseline were also statistically significantly associated with patient satisfaction, however improvement in IIQ-7 was $\operatorname{not}($ ANOVA $F=1.618, d f=2, p=0.204)$.

\section{Discussion}

Surgery for prolapse has a role in reconstructing the local anatomy and alleviating some symptoms but does not necessarily ensure optimal sexual function. Sexual function might be improved $(15,16,17)$, remains unchanged $(8,18)$ or worsened (19) after repair. Improvement in sexual function could also be due to emotional amelioration due to the cessation of incontinence $(20,21)$.

Most papers however only report on sexual function as a secondary finding. Most are retrospective in nature, and only a few have involved the use of a validated sexual function questionnaire (22). The prospective studies are either small with 3- 6 months follow up (8) or have used non condition specific questionnaires. Our study 
specific SF questionnaire with SF as the primary outcome.

257 Previously several retrospective and prospective studies have used either non validated SF questionnaires $(8,17)$ or self designed questionnaire or telephonic conversation. Recently condition specific validated sexual health questionnaires have been developed. At start of this trial the PISQ-31(Pelvic organ prolapse /Urinary incontinence Sexual Function Questionnaire) (including the short form PISQ-12) was the only validated condition specific (prolapse and UI) female sexual function questionnaire available. Other validated condition specific questionnaire that have been used to assess sexual function following pelvic floor surgery (e.g. Kings Health Questionnaire, ICIQ-VS) are quality of life questionnaires which include few questions addressing SF, they really deal with the overall impact of POP and/or UI surgery on the patients QoL. We therefore chose to use (the short form) PISQ-12 questionnaire for our study. However, we appreciate that this questionnaire only discriminates between women with and with out sexual dysfunction within the group of women with POP and UI and may not be optimal to detect SD following treatment as also concluded by Roos et al 2014 (23). We also understand that PISQ represents the positive effects of surgery well but does not reflect the possible negative effects of surgery on sexual function (16).

274 In our study population the mean PISQ-12 score was 30.54 (SD 6.55) with the 275 maximum possible score of 48 . Although a range of score for this instrument (PISQ 276 12) has not yet been established to classify severity of sexual dysfunction, we believe that our findings indicate that women enrolled in our study displayed a significant decrement in SF before POP and/or UI surgery. This observation is 
consistent with several prior studies that found reduced SF in women with UI and/or POP or both $(24,25,26)$.

281 The baseline PISQ-12 appears to be comparable to that reported by Brubaker in SISTEr Trial 2009 (mean 30.54) but lower than that reported by Glavind et al (mean 35.3) (27). This might be due to different baseline characteristics or different population.

We found statistically significant improvement in PISQ 12 score from baseline (30.54) to 6 months (33.45). Other studies which have reported statistical significant improvement in the score from baseline either have much smaller number of patients and shorter follow up.

In two different prospective study by Glavind et al (27) with short term follow up after prolapse surgery $(n=81)$ reported baseline PISQ12 of 35.2 with postop improvement with positive difference of 3.0 (SD 3.8). Brubaker also reported significant improvement in PISQ-12 scores from 31.6 (SD 6.85) to 36.85 (SD 5.89). In a long term study by Lindquist et all where 63 patients after tension free vaginal tapes were followed for 4 years ( $n=44$ ) used PISQ12 and quoted baseline mean PISQ12 of 33.8 which improved postoperatively(28).

Another prospective study by Thakar et al (16), in which 46 women were followed for 4 months post surgery showed significant improvement in SF after surgery for POP and UI at 4 months. Srikrishna et al (17) recruited 52 sexually active women and followed them up for 2 years using the GRISS and KHQ questionnaires, concluding that SF improved following surgery for POP with or out UI procedure. The results of the above two studies are not comparable as they used different questionnaires. 
302 In a study by Paul et al (8) where 51 patients followed for 6 months, found that SF as measured by FSFI and sexual frequency were unchanged following vaginal surgery for pelvic organ prolapse with or without UI surgery, despite improvement in the stage of prolapse and incontinence symptoms. Weber et al 2005 reported that SF and satisfaction improved or did not change in most women after surgery for prolapse and /or UI. Rogers et al (15) reported mixed results with improved SF in 68 $\%$ of women and worsened function in $32 \%$ using 2 validated, condition specific questionnaire (PISQ-12 and IIQ-7) preoperatively and 3 and 6 months after surgery in 102 women with a mean age of 47 years. Similar to our study they observed no differences in the total SF scores between women who underwent POP and UI surgery and those who had only UI or only POP surgery.

We found statistically significant improvement in PISQ-12 score from baseline to 6 months with a positive score of 2.91 . The minimum clinically important difference for the PISQ-12 is not yet determined. We observed positive improvement in SF scores by PISQ-12. Sloan et al proposed that a change of greater than half of the SD of the pre intervention score is a conservative estimate of an effect size that is clinically meaningful when using QOL questionnaires. (29).

We observed no further improvement in PISQ-12 score after 6 months. This suggests that any improvement in SF due to surgery is generally seen within the first 6-months; however the effect does appear to be maintained up to 1-year. Other studies using self designed non-validated questionnaire or much smaller numbers (15) have shown stability in SF outcomes over follow up period. We therefore suggest following this and our findings that assessment at 6 or 12 months are unlikely to be significantly different and the 6 month follow up can be used for comparison. 
327 Success of surgery was defined as patient satisfaction. In our study improvement in PISQ-12 was observed in women with successful surgery and hence associated with patient satisfaction postoperatively. This was seen in all three subgroups. Improvement in SF was strongly influenced by the outcome of surgery i.e. patient satisfaction. Patient who were satisfied with their surgical outcome reported improvement in PISQ-12 score compared to those who were not either because of failure in improvement of symptom or new onset symptom like SUI following POP surgery. Patient who reported improvement in UDI 6 and VS scores also reported high satisfaction with their surgical outcome. It may be the presence or absence of Urinary symptoms rather than surgical technique which defines sexual function (26).

The numbers in each subgroup of surgery type were too small to make any comment on whether one technique/surgery improves SF more than the others. In our study we saw significant improvement in all groups of women with or without incontinent and hence can conclude that SF improves after surgery not only due to improvement in UI scores but also due to amelioration in symptoms due to POP.

In our study we found significant improvement in UDI and IIQ 7 in the POP only group where no UI surgery was performed and also significant improvement in VS score in the UI only group where no prolapse surgery was performed. This may have contributed to improvement in the PISQ-12 score post operatively in both the POP only and UI only groups (27). In a cohort of 1267 sexually active women Tok et al (30) found that women with prolapse had lower SF scores than those without the POP due to fear of UI during intercourse and also avoidance of sexual intercourse 350 due to POP. It is therefore understandable that correcting the POP and improving 
351 the body image and ameliorating the symptoms should lead to improvement in the 352 SF.

353 We found improvement in PISQ-12 post operatively irrespective of technique or type 354 of surgery performed for UI. Improvement in UI scores/symptoms was associated with patient satisfaction. Whilst our cohort size may have been too small to look for differences in surgical techniques, our findings are consistent with other authors. Brubaker 2009(26) (SISTEr trial) concluded SF improves after successful surgery for $\mathrm{UI}$ and was irrespective of type/technique of UI surgery and also stage of pop or with/out concomitant POP surgery.

Our study has lots of strength. It is a prospective study with a large number of patients. We have used a disease specific validated questionnaire PISQ-12. We have followed up our patients for 1 year postoperatively and have used multiple validated indices of bladder, POP and sexual function

We acknowledge the limitations to our study. There is no normative data for PISQ-12 established and questionnaire only demonstrates the effect of intervention (10). As this is only an observational study it is not possible to have a definite conclusion that it was the intervention that led to improvement. Degree of distress cannot be established as condition specific questionnaire measuring distress is not available at present (16). Sexual questionnaire IUGA Revised (PISQ-12 R) was not used as this was not available at the time when study was performed

371 The presence of POP and /or UI rather than severity of the problem or subtype of POP may impact SF. We did not do any objective follow up for prolapse so are unable to comment if improvement in sexual function as reported by patients is due to functional improvement rather than secondary to objective improvement in UI and 
375 Ior POP (31). Srikrishna et al (17) objectively assess women at follow up and found 376 that the women with better supported pelvic floor were less likely to have sexual 377 dysfunction.

378 We however instead used validated IIQ7 and VS questionnaires which evaluate the 379 impact of POP and UI on social function. This may not exactly represent objective 380 evidence of cure of UI and POP however, they do assess in a standardised and 381 validated way the patient's overall improvement and perception of success of 382 surgery. Thus IIQ7 and VS scores are relevant to study for sexual function after treatment of UI and or POP and are representative of successful treatment of POP and or UI surgery (15).

We also acknowledge that there were women who did not complete the forms at recruitment and follow up as they found it too embarrassing. However, our remaining cohort still gives us a larger sample than other reported studies.

\section{Conclusion}

Sexual function improves after surgery for POP and UI in the majority of patients. This improvement is strongly positively associated with patient satisfaction with the surgery. Improvement is seen by 6 months and tends to be maintained at 1 -year.

Our study will help in counselling women with POP and/or UI undergoing surgery about potential improvement in SF. 
References:

400

401

402

403

404

405

406

407

408

409

410

411

412

413

1. Laumann EO, Paik A, Rosen RC Sexual dysfunction in the United States: prevalence and predictors JAMA 1999281 537-44 doi:10.1001/jama.281.6.537.

2. Fertility and Sterility $\square$ Vol. 88, No. 5, November 2007 Female sexual dysfunction: classification, pathophysiology, and management Rupesh Raina, M.D.,Geetu Pahlajani, M.D.,Shazia Khan, M.D.,Sajal Gupta, M.D., Ashok Agarwal, Ph.D., and Craig D. Zippe, M.D.

3. Swift SE (2000). (2000) Distribution of pelvic organ support in a population of female

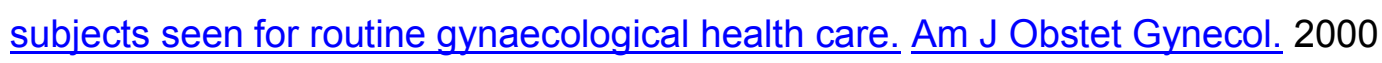
Aug;183(2):277-85.

4. Swift S, Woodman P, O'Boyle A, Kahn M, Valley M, Bland D, Wang W, Schaffer J (2005) Pelvic Organ Support Study (POSST): the distribution, clinical definition, and epidemiologic condition of pelvic organ support defects. Am J Obstet Gynecol. 2005 Mar;192(3):795-806.

5. Jolleys JV (1988) Reported prevalence of urinary incontinence in women in a general practice. Br Med J (Clin Res Ed). 1988 May 7;296(6632):1300-2.

6. Fialkow MF, Newton KM, Lentz GM, Weiss NS (2008) Lifetime risk of surgical management for pelvic organ prolapse or urinary incontinence... Int Urogynecol J Pelvic Floor Dysfunct. 2008 Mar;19(3):437-40. Epub 2007 Sep 26.

7. Barber MD, Visco AG, Wyman JF, Fantl JA, Bump RC; Continence Program for Women Research Group (2002) Sexual function in women with urinary incontinence and pelvic organ prolapse. Obstet Gynecol. 2002 Feb;99(2):281-9 
8. Pauls RN, Silva WA, Rooney CM, Siddighi S, Kleeman SD, Dryfhout V, Karram MM (2007) Sexual function after vaginal surgery for pelvic organ prolapse and urinary incontinence.. Am J Obstet Gynecol. 2007 Dec;197(6):622.e1-7.

9. Salonia A, Zanni G, Nappi RE, Briganti A, Dehò F, Fabbri F, Colombo R, Guazzoni G, Di Girolamo V, Rigatti P, Montorsi F (2004) Sexual dysfunction is common in women with lower urinary tract symptoms and urinary incontinence: results of a cross-sectional study. Eur Urol. 2004 May;45(5):642-8; discussion 648

10. Rogers RG, Kammerer-Doak D, Villarreal A, et al. (2001) A new instrument to $\underline{\text { measure sexual function in women with urinary incontinence or pelvic organ }}$ prolapse. Am J Obstet Gynecol 2001; 184:552

11. Handa VL, Cundiff G, Chang HH, Helzlsouer KJ (2008) Female sexual function and pelvic floor disorders.. Obstet Gynecol. 2008 May;111(5):1045-52. doi: 10.1097/AOG.0b013e31816bbe85

12. Nappi R, Salonia A, Traish AM, van Lunsen RH, Vardi Y, Kodiglu A, Goldstein I. (2005) Clinical biologic pathophysiologies of women's sexual dysfunction. J Sex Med. 2005 Jan;2(1):4-25

13. Althof SE, Dean J, Derogatis LR, Rosen RC, Sisson M (2005) Current Perspectives on the Clinical Assessment and Diagnosis of Female Sexual Dysfunction and Clinical Studies of Potential Therapies: A Statement of Concern. J Sex Med 2005;48:642-9

14. Su TH, Lau HH, Huang WC, Chen SS, Lin TY, Hsieh CH, Yeh CY. (2009) Short term impact on female sexual function of pelvic floor reconstruction with the Prolift procedure. J Sex Med. 2009 Nov;6(11):3201-7. doi: 10.1111/j.17436109.2009.01399.x. Epub 2009 Jul 21

15. Rogers RG, Kammerer-Doak D, Darrow A, Murray K, Qualls C, Olsen A, Barber M (2006) Does sexual function change after surgery for stress urinary incontinence 
and/or pelvic organ prolapse? A multicenter prospective study. Am J Obstet Gynecol 195(5):e1-e4

16. Thakar R, Chawla S, Scheer I, et al. (2008) Sexual function following pelvic floor surgery. Int J Gynaecol Obstet 2008; 102:110.

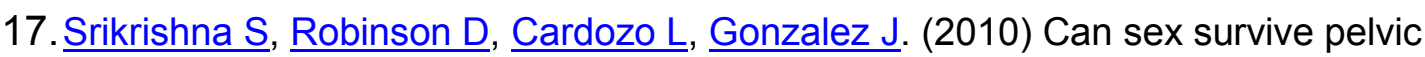
floor surgery? Int Urogynecol J. 2010 Nov;21(11):1313-9. doi: 10.1007/s00192-0101198-x. Epub 2010 Jun 25.

18. Occhino JA, Trabuco EC, Heisler CA, Klingele CJ, Gebhart JB. (2011) Changes in vaginal anatomy and sexual function after vaginal surgery. Int Urogynecol J. 2011 Jul;22(7):799-804. doi: 10.1007/s00192-011-1386-3. Epub 2011 Mar 17

19. Helström L, Nilsson B (2005) Impact of vaginal surgery on sexuality and quality of life in women with urinary incontinence or genital descensus. Acta Obstet Gynecol Scand. 2005 Jan;84(1):79-84.

20. Hasse P, Skidstead ,L (1988) Influence of operations for stress incontinence and/or genital descensus on sexual life. Acta Obstet Gynecol Scand, 1988;67(7):659-61

21. Lemack G E, Zimmern P E (2000) Sexual function after vaginal surgery for stress incontinence: results of a mailed questionnaire. Urology, 56: 223, 2000

22. Neill C., Abdel-Fattah M, Ramsay I N (2009), Sexual function and vaginal surgery. The Obstetrician \& Gynaecologist, 11: 193-198. doi:10.1576/toag.11.3.193.27504

23. Roos AM, Thakar R, Sultan AH, de Leeuw JW, Paulus AT (2014) The impact of pelvic floor surgery on female sexual function: a mixed quantitative and qualitative study.. BJOG. 2014 Jan;121(1):92-100; discussion 101. doi: 10.1111/14710528.12412. Epub 2013 Sep 10 
24. Barber MD, Visco AG, Wyman JF, Fantl JA, Bump RC; Continence Program for Women Research Group (2002) Sexual function in women with urinary incontinence and pelvic organ prolapse..Obstet Gynecol. 2002 Feb;99(2):281-9.

25. Weber AM, Walters MD, Schover LR, Mitchinson A. (1995) Sexual function in women with uterovaginal prolapse and urinary incontinence. Obstet Gynecol 1995; 85:483.

26. Brubaker L, Chiang S, Zyczynski H, Norton P, Kalinoski DL, Stoddard A, Kusek JW, Steers W Urinary Incontinence Treatment Network. The impact of stress incontinence surgery on female sexual function.;. Am J Obstet Gynecol. 2009 May;200(5):562.e1-7. doi: 10.1016/j.ajog.2008.11.017. Epub 2009 Mar 16

27. Glavind K, Sexual function in women before and after surgery for pelvic organ prolapse. AOGS 2015; 94: 80-85 Int Urogynecol J. 2016 Oct;27(10):1571-6. doi: 10.1007/s00192-016-3004-x. Epub 2016 Mar 18.

28. Lindquist AS, Glavind K Long-term follow-up of sexual function in women before and after tension-free vaginal tape operation for stress urinary incontinence. IUJ 2016: 27: 1571-76

29. Sloan J, Symonds T, Vargas-Chanes D, Fridley B: Practical Guidelines for Assessing the Clinical Significance of Health-Related Quality of Life Changes within Clinical Trials. Drug Information Journal 2003,37(1):23-31

30. Tok EC1, Yasa O, Ertunc D, Savas A, Durukan H, Kanik A.(2010) The effect of pelvic organ prolapse on sexual function in a general cohort of women. J Sex Med. 2010 Dec;7(12):3957-62. doi: 10.1111/j.1743-6109.2010.01940.x.

31. Lowenstein L, Gamble T, Sanses TV, et al. (2010) Changes in sexual function after treatment for prolapse are related to the improvement in body image perception. $\mathrm{J}$ Sex Med 2010; 7:1023. 
496

497

498

499

500

501

502

503

504

505

506

507

508

509

510

511

512 Appendix 1 
Department of Urogynaecology

Southern General Hospital

1345 Govan Road

Glasgow G51 4TF

\section{PATIENT SATISFACTION QUESTIONNAIRE}

1. How satisfied are you with your surgery?

- Not satisfied

- Equivocal

- Satisfied

- Very satisfied

2. Have you had any postoperative complications since you have been discharged?

- Infection

- Bleeding requiring hospital attendance/admission

- Mesh erosion

- Others

3. How much do you think your symptoms have resolved?

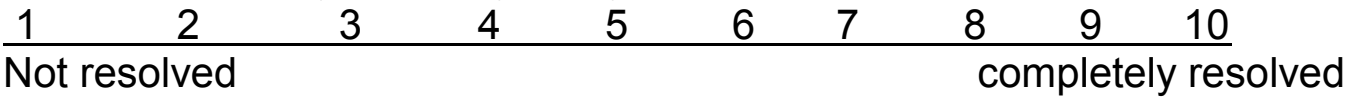

4. Have you needed any further surgery for your symptoms?

- No

- Yes .......please specify

5. What surgery and when did you get the repeat surgery?

Thanks for your time and help

Urogynaecology Unit

Greater Glasgow and Clyde 
